\title{
Correction to: Optimality criteria for futility stopping boundaries for group sequential designs with a continuous endpoint
}

\author{
Xieran $\mathrm{Li}^{1}$, Carolin Herrmann ${ }^{1,2}$ and Geraldine Rauch ${ }^{1,2^{*}}$
}

\section{Correction to: BMC Med Res Methodol 20, 274 (2020) \\ https://doi.org/10.1186/s12874-020-01141-5}

Following publication of the article [1], it was noted that due to a typesetting error the old version of Fig. 1 is displayed with the correct version of Fig. 1, and it should be deleted.

The correct Fig. 1 and caption have been included in this correction, and the original article has been corrected.

Published online: 25 November 2020

\section{Reference}

1. Li X, et al. Optimality criteria for futility stopping boundaries for group sequential designs with a continuous endpoint. BMC Med Res Methodol. 2020;20:274.

The original article can be found online at https://doi.org/10.1186/s12874020-01141-5.

* Correspondence: geraldine.rauch@charite.de

'Charité - Universitätsmedizin Berlin, corporate member of Freie Universität Berlin, Humboldt-Universität zu Berlin, and Berlin Institute of Health, Institute of Biometry and Clinical Epidemiology, Charitéplatz 1, 10117 Berlin, Germany ${ }^{2}$ Berlin Institute of Health (BIH), Anna-Louisa-Karsch-Str. 2, 10178 Berlin,

Germany

(c) The Author(s). 2020 Open Access This article is licensed under a Creative Commons Attribution 4.0 International License, which permits use, sharing, adaptation, distribution and reproduction in any medium or format, as long as you give appropriate credit to the original author(s) and the source, provide a link to the Creative Commons licence, and indicate if changes were made. The images or other third party material in this article are included in the article's Creative Commons licence, unless indicated otherwise in a credit line to the material. If material is not included in the article's Creative Commons licence and your intended use is not permitted by statutory regulation or exceeds the permitted use, you will need to obtain permission directly from the copyright holder. To view a copy of this licence, visit http://creativecommons.org/licenses/by/4.0/ The Creative Commons Public Domain Dedication waiver (http://creativecommons.org/publicdomain/zero/1.0/) applies to the data made available in this article, unless otherwise stated in a credit line to the data. 


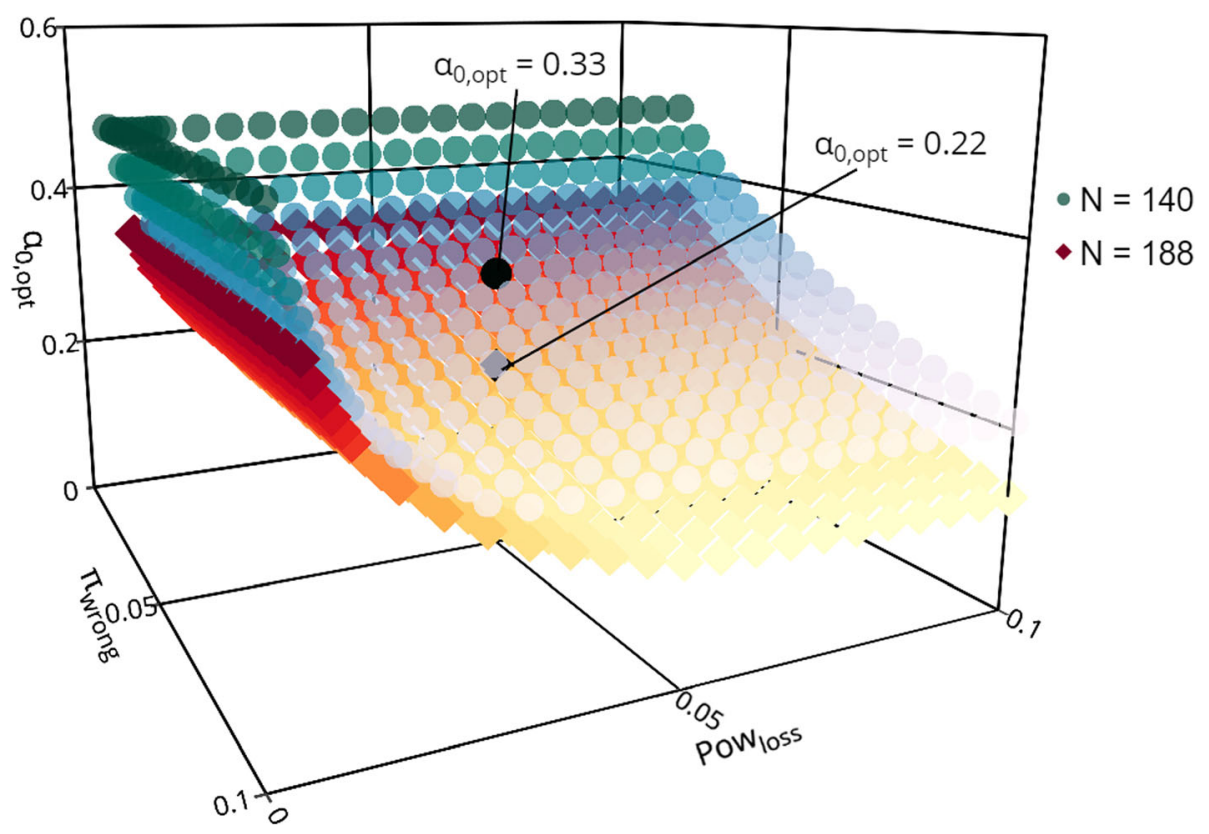

Fig. 1 The "optimal" futility boundary $a_{0, o p t}$ as a function of the admissible parameters Pow loss and $\pi_{\text {wrong }}$ for $N=140$ (blue dots) and $n=188$ (red squares). The black symbols highlight the "optimal" futility boundaries for Pow loss $=0.05$ and $\pi_{\text {wrong }}=0.05$ 